\title{
Dispensaries: the Wild West of Vancouver
}

$\mathrm{V}$ ancouver has entered unchartered territory as the first Canadian city to regulate marijuana dispensaries, with proponents arguing that regulation protects people's health and restricts access.

The chief medical health officer for Vancouver Coastal Health, Dr. Patricia Daly, who helped inform the decision to regulate, says that "city council may be seen as the Wild West, but they're stepping in to reduce potential harms associated with the complaints they had from the community."

Over the past few years, 100 marijuana dispensaries have opened in Vancouver. Only 25 licensed producers, which deliver their product by mail, have been approved by Health Canada to sell medicinal marijuana from federally sanctioned growers. The remainder presumably obtain their cannabis from black market sources. These businesses were run without any city bylaws restricting how the illegal drug was sold.

"By regulating this, people under 19 won't be allowed in these places, they won't be selling edible products, and it's actually going to improve the situation from what it is currently," Daly says.

The new city bylaws ban the sale of marijuana in baked goods or candies. Daly directed city council to emerging evidence from the United States, showing unintended exposure among young children who consumed edibles has increased in states that have legalized marijuana for recreational use. "The lesson from the US is that the edible products are a problem and they probably should have been more strictly regulated."

The federal government opposes the city's decision and hopes that the police will enforce the law prohibiting marijuana, but Vancouver Police Chief Constable Adam Palmer has made it clear that shutting down dispensaries is a low priority.

Dispensaries and compassion clubs are considered illegal by the federal gov-

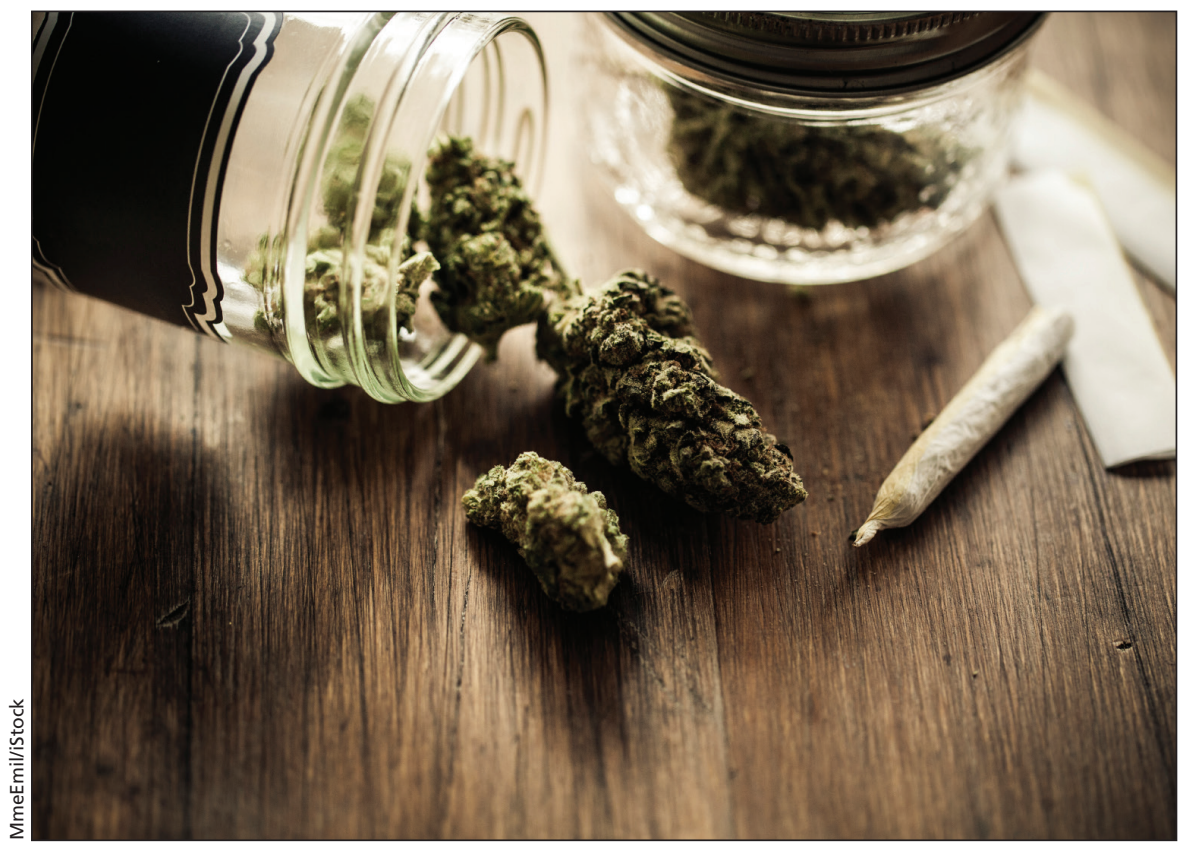

Dispensaries selling illegal marijuana in Vancouver must now have a business licence.

ernment; the only legal way to obtain cannabis is for a "health care practitioner" to complete a medical document for the patient. Doctors are, in effect, the gatekeepers of medical marijuana.

The President of Doctors of BC, Dr. Charles Webb, says that physicians have no training in medical marijuana composition, how it will alleviate symptoms of an illness or what the long-term effects might be. "Doctors really have no guidance, or instruction, or training in how to prescribe it."

Webb says that Vancouver's new regulations won't affect doctors.

However, the drug may become more accessible within the province. Victoria city council is considering following Vancouver's lead in regulating its 19 dispensaries.

Under Vancouver's bylaw, dispensaries must pay $\$ 30000$ a year for a business licence, while compassion clubs, which are usually not-for-profit, member-run and offer wellness services, must pay $\$ 1000$. The new bylaw bans dispensaries from operating within 300 metres of schools, community centres and other marijuana shops.
Daly acknowledges that a lot of people are visiting the shops for recreational purposes. She asked that some of the licensing funds go toward educational programs in schools and city council agreed. "We want [youths] to understand the harm associated with marijuana. So they have good information and can make an informed choice about whether to use this product."

The dispensaries will also have to provide information to their clients outlining who shouldn't use marijuana for medicinal purposes, including people with schizophrenia and pregnant women.

Not everyone agrees with Vancouver's new regulations. They pose a public health threat, says Pamela McColl, spokesperson for Smart Approaches to Marijuana, a national advisory board made up of researchers and physicians. "Any move to legitimize storefronts is a move towards normalization and commercialization. It will increase use by youth and other people."

The city's former drug-policy coordinator for 12 years, Donald MacPherson, disagrees and says that the supply of cannabis would remain the same even if 
all of Vancouver's dispensaries were to close tomorrow. "All that's happening is that part of the market is becoming more above ground and regulated."

He compares Vancouver's dispensaries with Insite, a supervised injection clinic introduced by the city in 2003 . "It's a municipality trying to come up with a solution that works with the locality." MacPherson says that dispensaries have been around for many years.

Just because dispensaries are now regulated doesn't mean that people will become addicted to marijuana, adds Dr. Benedikt Fischer, a senior scientist at the Centre for Addiction and Mental Health in Toronto. He compares the current marijuana situation with the temperance movement and the prohibition of alcohol in the early 20th century.

Back then, the only place people could get alcohol was in the pharmacies for supposed medicinal purposes. "These weren't chronically ill people discovering that alcohol was a medical cure for the chronic illness they had; it's just a substance they wanted to consume for a variety of reasons."

He says that with marijuana, there is actually some evidence of therapeutic benefits, although more research needs to be done. The difficulty is that many "medical marijuana users are using it for psychological issues like stress, sleep problems or well-being, which are not so easy to categorize in terms of the symptoms and the outcomes."

Many agree that more research is needed, but while everyone waits for that to happen, Vancouver is taking matters into its own hands. - Shannon Lough, CMAJ

CMAJ 2015. DOI:10.1503/cmaj.109-5116 